\title{
Original inhibition method of excessive synthesis of pro-inflammatory cytokine of tumour necrosis factor $\alpha$
}

\author{
ALEXANDER ZINCHUK ${ }^{1}$, OLGA HOLUBOVSKA ${ }^{2}$, ANDRIJ SHKURBA ${ }^{2}$, ROMAN HRYTSKO ${ }^{l}$, \\ OLGA VOROZHBYT ${ }^{l}$, MYKHAILO RICHNIAK ${ }^{l}$, BORYS HERASUN ${ }^{l}$
}

'Department of Infectious Diseases, Danylo Halytsky Lviv National Medical University, Ukraine

${ }^{2}$ Department of Infectious Diseases, O.O. Bohomolets National Medical University, Kyiv, Ukraine

\begin{abstract}
Influence on pro- and anti-inflammatory cytokines of an ill person is an urgent aspect of treatment of many diseases. For inhibition of synthesis of a high level of pro-inflammatory cytokines, medications which are recombinant monoclonal antibodies, especially to tumour necrosis factor $\alpha(T N F-\alpha)$, are used. However, these methods of treatment require further improvement by elaborating new approaches with a wider spectrum of influence on the immune system.

A completely new method of reduction in high activity of TNF- $\alpha$ with the method of intradermal autoleukocyte immunization is presented in the article. Investigation was performed in a group of patients with psoriasis (24) with a high level of TNF- $\alpha$ in the blood (over $30 \mathrm{pg} / \mathrm{ml}$ ). Simultaneously such investigation was performed on patients with psoriasis (9) without TNF- $\alpha$ detected $(0 \mathrm{pg} / \mathrm{ml})$.

As a result of immunization, a significant reduction in TNF- $\alpha$ occurred in all patients with its high level, in $16(66.7 \%)$ from 24 patients - to $0-5 \mathrm{pg} / \mathrm{ml}$. The level of reduction and duration of the achieved effect was of an individual character and requires further investigation. However, the achieved results prove the expediency of administration of this immunization method for patients requiring reduction of $T N F-\alpha$ synthesis.

However, the content of TNF- $\alpha$ in blood serum could not be detected in most patients with a low level of cytokine (in 6 from 9) after immunization (as well as before immunization), but an increase in its level from 0 to $5-8 \mathrm{pg} / \mathrm{ml}$ was observed in 3 patients. On the basis of the conducted research, the authors suggest that the influence of immunization on cytokine synthesis depends on the condition of immune cells and correlation of pro- and anti-inflammatory cytokines in a patient's skin.
\end{abstract}

Key words: cytokines, $T N F-\alpha$, intradermal autoleukocyte immunization, psoriasis, rheumatoid arthritis.

(Cent Eur J Immunol 2015; 40 (3): 345-348)

\section{Introduction}

The contemporary strategy of treatment of certain inflammatory processes implies cytokine and anti-cytokine therapy. First of all, it concerns inhibition of synthesis of pro-inflammatory cytokines. After elaboration of the technology of monoclonal formation of antibodies, they are used for inhibition of cytokine activity, especially tumor necrosis factor $\alpha$ (TNF- $\alpha$ ). The range of use of anti-cytokine monoclonal antibodies is practically (and even more theoretically) broad, especially it concerns antibodies against TNF- $\alpha$. Tumour necrosis factor $\alpha$ is known to possess a considerable number of effects depending on its concentration. In high concentration, TNF- $\alpha$ acts as a mediator, resulting in development of an endotoxin-induced septic shock, is capable to inhibit lipoprotein lipase of fatty tissue, promoting development of cachexia, and is the cause of cell necrosis of certain tumours. Tumour necrosis factor $\alpha$ intensifies production of prostaglandins, thus realizing its toxic effects. A high level of TNF- $\alpha$ not only promotes the development of cachexia and is the cause of tumour necrosis; it can also play a negative role in many other pathological conditions [1-8]. This is caused by a very broad spectrum of its properties: TNF- $\alpha$ is considered to be the leading initiator of the inflammatory process by stimulating many pro-inflammatory cytokines [1,2], has an impact on lymphocytes, neutrophils, platelets, fibroblasts and many other body cells, acts on indices of lipid metabolism, functions of the endothelium, and resistance to insulin [9].

Correspondence: Borys Gerasun, Department of Infectious Diseases, Danylo Halytsky Lviv National Medical University Pekarska 54, 79010 Lviv, Ukraine, tel. +38 06690827 598, fax +38 03227692 20, e-mail: gerab@3g.ua 
High activity of pro-inflammatory cytokines is characteristic for patients with a chronic heart failure of various aetiologies [1, 10, 11], alcoholic hepatitis [5-7], rheumatoid arthritis [12], and psoriasis [13, 14].

Although aetiology and pathogenesis of psoriasis have not been completely studied yet, activation of CD4+ T-lymphocytes is considered to play an important role in the pathological process, resulting in intensified synthesis of numerous pro-inflammatory cytokines, especially TNF- $\alpha$. Thus, a decreased activity of TNF- $\alpha$ should have a positive impact on the course of severe forms of psoriasis.

The role of TNF- $\alpha$ in pathogenesis of such diseases as rheumatoid arthritis and psoriasis is confirmed by the efficacy of medication methods of pro-inflammatory cytokine inhibition. Thus, the results of administration of medical preparations containing antibodies to cytokines in mono- or combined therapy of rheumatoid arthritis confirm improvement of the clinical picture, which was observed in most patients immediately after completion of a 5-day treatment course, the most effective was inhibition of activity of TNF- $\alpha$ factor [12]. Similar results were also observed in other diseases.

Introduction of cytokine drugs is one of the most important achievements in medicine. Their basic peculiarity is the pathogenic direction and high treatment efficacy. However, it is necessary to mention that biological TNF- $\alpha$ inhibitors are foreign proteins, which may result in allergic reactions [15-17] and accelerate elimination of cytokine antibodies [18].

The advantage of antibodies over certain determinants of immunocompetent cells (for example, chimeric monoclonal antibodies to CD20 antigen of B-lymphocytes) is a distinct immunological direction. However, they are known to result in certain inhibition of immune response to concomitant infectious diseases.

In our previous investigations on the treatment of autoimmune processes, in particular, systemic vasculitis, ef-

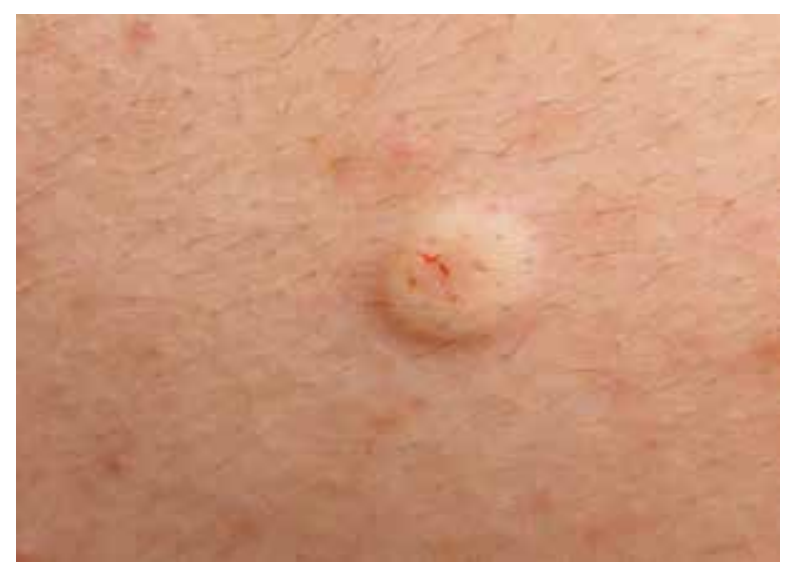

Fig. 1. Site of an intradermal injection of autoleukocytes (resembling "lemon peel") ficacy of intradermal autoleukocyte immunization was established, which was regarded as a personal method of the cell therapy. A positive influence on the clinical picture of systemic vasculitis and other autoimmune conditions [1924] theoretically coincides with the influence on the activity of pro-inflammatory cytokines. It was the cause of the trial on intradermal autoleukocyte immunization as the way of decreasing the high level of TNF- $\alpha$ in blood serum [25].

The aim of our research was to study possibilities of inhibition of TNF- $\alpha$ activity using own body's biofactors with a broad spectrum of biological influence.

\section{Material and methods}

\section{Patients}

A group of patients with psoriasis with a high level of this cytokine $(\geq 30 \mathrm{pg} / \mathrm{ml}$ ) was selected for the study of intradermal autoleukocyte immunization for TNF- $\alpha$ synthesis. The group included 24 patients with psoriasis aged 18-58, including 11 females and 13 males. The patients were being monitored for psoriasis by dermatologists from 3 to 15 years.

Patients with typical clinical pictures of psoriasis were chosen randomly without consideration of peculiarities of the clinical course and severity of the disease, the only pre-condition was an increased level of TNF- $\alpha$ in the blood. Simultaneously 9 patients with psoriasis without detected TNF- $\alpha$ in blood serum were examined. Patients, who did not receive medications influencing the cytokine level, were also involved in the research.

Tumour necrosis factor $\alpha$ in blood serum was detected using the method based on an immunoenzymatic sandwich microplate assay using mono- and anticlonal antibodies to TNF- $\alpha$ (manufacturer "Vector Best", Russia).

The investigated method of reduction of pro-inflammatory cytokine activity implies two stages: isolation of leukocytes from the peripheral blood and their intradermal introduction into a patient's body. The mechanism of action of intradermal autoleukocyte immunization was described previously [19-24].

Treatment was compatible with local ethics committee.

Leukocytes isolation. Leukocytes were isolated by precipitation of a patient's heparinized peripheral venous blood with a high level of TNF- $\alpha$ in blood serum. Thus, venous blood in the volume of 100-150 ml was placed into glass with Heparinum petricum (Heparins-Richter) at a dose of 50 units of heparin per $10 \mathrm{ml}$ of blood. This mixture is poured into $10 \mathrm{ml}$ glasses at $45^{\circ}$ angle and incubated in thermostat at $37^{\circ} \mathrm{C}$ for $90-140$ minutes. Blood was carefully aspirated; leukocytes were precipitated by centrifuging at $200 \mathrm{~g}$ during 7-8 minutes. The precipitate was resuspended in 1.0-1.5 ml of a patient's blood serum.

Manipulations were performed in sterile conditions.

Immunization. Autocells of peripheral blood were injected to patients with an increased level of TNF- $\alpha$ in 
blood serum (>30 pg/ml). Autoleukocytes were injected intradermally (resembling "lemon peel") at a dose of 0.1 $\mathrm{ml}$ in 8-12 points into the skin of the back (between scapulae). The level of TNF- $\alpha$ in blood serum was measured $10-12,30,60$ and 180 days after immunization. Then, the level of cytokine was monitored, in case of need, immunization was repeated (individually, considering peculiarities of response to the procedure).

\section{Results of investigation and their discussion}

Influence of autoleukocyte immunization on intensive synthesis of TNF- $\alpha$ in blood serum is confirmed by the results of monitoring of its level before and after immunization (Table 1).

The data, presented in Table 1, show that a reduction in the TNF- $\alpha$ level was observed in all patients $(100 \%)$ with its intensive synthesis. In most of them (16 from 24; $66.7 \%$ ) the level of TNF- $\alpha$ after immunization ranged within $0-5 \mathrm{pg} / \mathrm{ml}$. However, in some patients, despite a considerable decrease, the level of TNF- $\alpha$ remained high. Thus, in 13 patients with a baseline level of TNF- $\alpha$ over $200 \mathrm{pg} / \mathrm{ml}$, cytokine remained within 30-100 pg/ml in $6(46.2 \%)$. Such patients require additional analogical manipulations.

Duration of the effect was individual. Thus, in 4 patients from 24 (16.7\%), synthesis of TNF- $\alpha$ did not resume throughout 8 months of monitoring, in others it started to increase 1.5-3 months after single immunization. These patients were repeatedly immunized with leukocytes, but in smaller doses (cells were isolated from $50-60 \mathrm{ml}$ of blood). The process of increase of TNF- $\alpha$ synthesis decreased in such patients.

Autoleukocyte immunization had a positive impact on the clinical course of the disease. Thus, actually the general condition improved in all patients, skin manifestations of the disease decreased (or temporarily disappeared). In patients with psoriatic arthritis, joint pain also decreased. However, influence on clinical manifestations of the disease requires a further thorough study.

After immunization the level of TNF- $\alpha$ could not be detected in blood serum of most patients with a low level of cytokine (in 6 from 9) (as well as before immunization), but a considerable increase in the synthesis of its content occurred in 3 patients (from 0 to $5-8 \mathrm{pg} / \mathrm{ml}$ ).

The latter enables us to suppose that the influence of intradermal autoleukocyte immunization on TNF- $\alpha$ synthesis may depend on the condition of immunocompetent cells and correlation of regulatory cytokines (pro-inflammatory and anti-inflammatory) in a patient's blood. The mechanism of influence of autoleukocyte immunization on autoimmune processes was described previously [21, $23,26]$. An important aspect is the process of Jerne network correction - idiotypic-anti-idiotypic regulation of immune response, which is confirmed by an increased amount of anti-idiotypic antibodies in a patient's blood serum after leukocyte immunization. Besides, activation of CD3+, CD8+, CD25+-lymphocytes and CD3+, CD8+, CD28+-lymphocytes occurs in this manipulation simultaneously with the blockade of Fc-receptors, as well as glycoprotein and lectin receptors on B-lymphocytes [27]. Although these factors should influence the synthesis of cytokines, it is obvious that solution to this aspect requires further special investigations. It is also expedient to study the influence of the procedure on the condition of other pro-inflammatory and anti-inflammatory cytokines.

No doubt, the suggested technique requires further detailed elaboration for more precise dosage and scheme of immunization, considering clinical manifestations of the disease and individual reaction to the procedure. However, even at present the obtained results confirm the expediency of this method inclusion into the complex treatment of diseases with a high activity of TNF- $\alpha$. Besides, a significantly broader range of this procedure results in a reduction of

Table 1. Influence of autoleukocyte immunization on TNF- $\alpha$ level (over $30 \mathrm{pg} / \mathrm{ml}$ ) in blood serum of patients with psoriasis (based on results of examination 30 days after single autoleukocyte immunization)*

\begin{tabular}{|c|c|c|c|c|c|}
\hline \multirow{3}{*}{$\begin{array}{l}\text { Level of TNF- } \alpha \text { before } \\
\text { autoleukocyte immunization } \\
\qquad(\mathrm{pg} / \mathrm{ml})\end{array}$} & \multirow{3}{*}{$\begin{array}{c}\text { Number } \\
\text { of patients }\end{array}$} & \multicolumn{4}{|c|}{ Level of TNF- $\alpha 30$ days after autoleukocyte immunization (pg/ml) } \\
\hline & & $0-5$ & $30-50$ & $51-60$ & $61-100$ \\
\hline & & \multicolumn{4}{|c|}{ Number of patients } \\
\hline $30-50$ & 3 & 3 & & & \\
\hline $51-100$ & 2 & 2 & & & \\
\hline $150-200$ & 6 & 4 & 1 & 1 & \\
\hline $201-250$ & 5 & 3 & 2 & & \\
\hline$>250$ & 8 & 4 & 1 & 1 & 2 \\
\hline Total & 24 & $16(66.7 \%)$ & $4(16.7 \%)$ & $2(8.3 \%)$ & $2(8.3 \%)$ \\
\hline
\end{tabular}

*Decrease in the TNF- $\alpha$ level was registered already 10 days after autoleukocyte immunization, however, in some patients the influence of immunization intensified throughout a month. Thus, the results presented in the table are the results obtained 30 days after the treatment procedure. 
precipitating cold proteins - cryoglobulins [20,24] and, as opposite to antibodies-inhibitors of TNF- $\alpha$, may promote intensification of antiviral cell-mediated and humoral immunities [26]. And it is important for autoimmune processes, trigger factor of which can be viruses.

\section{Conclusions}

It has been established that intradermal immunization with autoleukocytes promotes inhibition of excessively intensive synthesis of pro-inflammatory cytokine - TNF- $\alpha$ in patients with various clinical forms of psoriasis, indicating the expediency of its administration in the form of monotherapy or inclusion to complex therapy of the diseases with high level of cytokines. However, the scheme of such therapy (dosage, frequency of manipulations, duration of intervals between procedures) requires further studies, taking into consideration peculiarities of the clinical course of the disease.

\section{The authors declare no conflict of interest.}

\section{References}

1. Murphy JE, Robert C, Kupper TS (2000): Interleukin-1 and cutaneous inflammation: a crucial link between innate and acquired immunity J Invest Dermatol 2000; 114: 602-608.

2. Boris LC, Steinke JW (2003): Cytokines and chemokines J Allergy Clin Immunol. 2003; 111 (2 Suppl): S460-S475.

3. Gupta S, Gollapudi S (2005): Molecular mechanisms of TNF-alpha-induced apoptosis in aging human T cell subsets. Int J Biochem Cell Biol 37: 1034-1042.

4. Tousoulis D, Antoniades C, Vassiliadou C, et al. (2005): Effects of combined administration of low dose atorvastatin and vitamin $\mathrm{E}$ on inflammatory markers and endothelial function in patients with heart failure. Eur J Heart Fail 7: 1126-1132.

5. Gao B, Bataller R (2011): Alcoholic liver disease: pathogenesis and new therapeutic targets. Gastroenterology 5: 15721585.

6. Miller AM, Horiguchi N, Jeong WI, et al. (2011): Molecular mechanisms of alcoholic liver disease: innate immunity and cytokines. Alcohol Clin Exp Res 2011; 35: 787-793.

7. Neuman MG (2003): Cytokines in alcoholic liver. Alcohol Res Health 2003; 27: 307-316.

8. Drannik HN (2010): Clinical immunology and allergology. Kiev, 2010.

9. Wellen KE, Gökhan S (2005): Hotamisligil. Inflammation, stress, and diabetes. J Clin Invest 115: 1111-1119.

10. Mann DL (2002): Inflammatory mediators and the failing heart: past, present, and the foreseeable future. Circ Res 91: 988-998.

11. Tabet JY, Lopes ME, Champagne S, et al. (2002): Inflammation, cytokines and anti-inflammatory therapies in heart failure. Arch Mal Coeur Vaiss 95: 204-212.

12. Sygydyn YA, Skurkovych BS, Lunina GV (1998): New approaches to biological immunomodulating therapy of rheumatoid arthritis: neutralization of basic cytokines, Therapeutic Archives 5: 32-37.
13. Granstein RD (2001): New treatments for psoriasis. N Engl J Med 345: 284-287.

14. Badokin VV (2005): Perspectives of administration of TNF inhibitors in psoriasis and psoriatric arthritis. Clinical pharmacological therapy, 14: 76-79.

15. Brimhall AK, King LN, Licciardone JC, et al. (2008): Safety and efficacy of alefacept, efalizumab, etanercept and infliximab in treating moderate to severe plaque psoriasis: a meta-analysis of randomized controlled trials. Br J Dermatol 159: $274-285$

16. Schellekens H (2002): Immunogenicity of therapeutic proteins: clinical implications and future prospects. Clin Ther 24: $1720-1740$.

17. Anderson PJ (2005): Tumor necrosis factor inhibitors: Clinical implications of their different immunogenicity profiles. Semin Arthritis Rheum 34: 19-22.

18. Lobo ED, Hansen RJ, Balthasar JP (2004): Antibody pharmacokinetics and pharmacodynamics. J Pharm Sci 2004; 93 : 2645-2668.

19. Herasun BA, Chopiak VV, Vorozhbyt OB (2006): Treatment of autoimmune disorders caused by chronic hepatitis B and $\mathrm{C}$ by means of autoleukocyte immunization. Mir Virusnykh Hepatitov Moscow 1: 13-18.

20. Chopyak VV, Hospodarskyi IY, Herasun BA (2006): Clinical algorythm of providing medical aid to patients with polyclonic (mixed) cryoglobulinemic syndrome - D 89.1. - Methodological guide of Ministry of Health of Ukraine, Kyiv, 2006.

21. Herasun BA, Andreychyn MA, Hrytsko RY, et al. (2012): Use of leukocytes in cell therapy. Gepatologia 2: 4-17.

22. Herasun BA, Kopets RA (2012): Application of the method of autoleukocytes 264 vaccination as the method of treatment of oligo- and astenozoospermia. UA97461 (2012).

23. Gerasun BA, Holubovska OA, Hrytsko RY, et al. (2014): Reduction of hyperproduction of thyroid autoantibodies in patients without disturbance of the thyroid function: new patents. Recent Pat Endocr Metab Immune Drug Discov 8:140-145.

24. Gerasun B, Kopets R, Hrytsko R, Gerasun O (2013): Correction of fertility disorders in patients with cryoglobulinemia. Cent European J Urol 2013; 66: 316-319.

25. Patent for useful model № 97493. Use of the method of autoleukocyte vaccination as the inhibition method of the synthesis of pro-inflammatory cytokine of TNF-alpha in patients with psoriasis. Herasun BA; Ukraine, published 10.03.2015.

26. Herasun BA, Hrytsko RY (2012): Original treatment method of frequently recurrent chronic herpetic infection caused by herpes simplex virus I and II types. Centr Eur J Immunol 37: 362-364.

27. Golab J, Jakobisiak M, Lasek W, Stoklosa T. Immunologia. Wydawnictwo Naukowe PWN, Warszawa 2007; 1-511. 